\title{
The Relationship between Stress and Counterproductive Work Behavior: Attachment Orientation as a Moderate
}

\author{
Lin Ma1, Wenli Li ${ }^{2 *}$ \\ ${ }^{1}$ School of Management, Jinan University, Guangzhou, China \\ ${ }^{2}$ Shenzhen Tourism College, Jinan University, Shenzhen, China \\ Email: *li_wl@sz.jnu.edu.cn
}

How to cite this paper: Ma, L. and Li, W.L. (2019) The Relationship between Stress and Counterproductive Work Behavior: Attachment Orientation as a Moderate. Open Journal of Social Sciences, 7, 413-423.

https://doi.org/10.4236/jss.2019.74033

Received: April 4, 2019

Accepted: April 26, 2019

Published: April 29, 2019

Copyright $\odot 2019$ by author(s) and Scientific Research Publishing Inc. This work is licensed under the Creative Commons Attribution International License (CC BY 4.0).

http://creativecommons.org/licenses/by/4.0/

\begin{abstract}
The dissertation is based on the stressor-emotion model, and creatively adopting attachment orientation as a moderator. This paper analyzes the sample data by issuing 400 questionnaires and then using SPSS22.0. The results show that work stress can positively predict the Counterproductive Work Behavior of employees. Attachment avoidance can moderate the relationship between work stress and CWB, and attachment anxiety has significant effect on the relationship between work stress and CWB. Research shows that the pressure in the workplace can not only cause employees' Counterproductive Work Behavior, but also cause negative affectivity of employees, which further leads to Counterproductive Work Behavior of employees, while attachment avoidance can effectively regulate the positive pressure of work stress. Therefore, to some extent, the possibility of anti-production behavior can be reduced.
\end{abstract}

\section{Keywords}

Job Stress, CWB, Attachment Anxiety, Attachment Avoidance

\section{Introduction}

In recent years, while China's economy has developed rapidly, labor conflicts and management pressures in enterprises have also intensified [1]. There were 73 incidents of strikes in China during the period of 2004-2010 [2], and there is an increasing trend. Among the members of the organization, a survey of managers in the United States in 1997 showed that $68.9 \%$ of managers said they had been attacked by subordinates [3], and another survey showed that $35 \%-55 \%$ 
Participants acknowledged that they had committed acts of theft, misappropriation of public funds, vandalism and absenteeism in the workplace [4].

These kinds of behaviors are called anti-production behaviors or counterproductive work behavior (CWB) which means the negative behaviors that employees perform in the workplace can cause harm to the organization and its members. A large number of studies have shown that CWB not only reduces the individual's job satisfaction, but also has negative influence on turnover. Why is there counterproductive work behavior? From the literature review, scholars have conducted in-depth research on this issue and achieved remarkable results. Studies found that differences in individual traits, and situations, and personality traits may lead to anti-production behavior [5]. On the other hand, the employees in the organization are also facing tremendous pressure. According to the 2014 China Workplace Energy Survey, 44\% of participants believe that they are under great work pressure. In some high-stress industries, more than $70 \%$ of practitioners suffer from psychological and physical problems due to excessive work stress. Excessive work stress not only harms people's physical and mental health, but also affects people's status and behavior in the workplace.

For the sake of the differences in individual traits, the individual's evaluation of stress and the adjustment of their own emotions are inconsistent. The occurrence of any external behavior may be affected by the inherent and stable personality traits of the individual, and the CWB is no exception. The attachment orientation presents a systematic pattern of intimate relationship expectations, emotions, and behaviors generated by the individual's attachment history. Related to this, the adult attachment orientation also reflects the general expectation of the individual's ability to cope with stressors and the rules that guide emotional responses to stress. Claudia's study found that attachment orientation effectively regulates individual behavioral responses to workload [6]. Different attachment orientations determine different attitudes towards self and others.

Therefore, the purpose of this article is to verify the relationship between job stress and counterproductive work behavior, as well as to analyze the function of attachment orientation between these two variables.

\section{Theoretical Framework and Research Hypotheses}

\subsection{Stress and Counterproductive Work Behavior}

Work stress refers to the process of creating a series of physiological, psychological and behavioral responses under the influence of personality and coping behaviors when the stressors of personal goals are threatened in a long-term and continuous manner in the work environment [7]. Existing researchs often use a stress-emotional model [8] to explain the negative consequences of work stress. According to the stress-emotional model, individuals will perceive certain special environmental events as events that threaten happiness, that is, work stressors. These stressors can cause stress perception in the individual's psychological, physiological or behavioral aspects, leading to corresponding behavioral 
responses. The theory also emphasizes that individual emotions play a vital role in the relationship between stress and the CWB.

In his early research, Spector found that individual frustration increases individual aggression and hostility, and anger can easily lead to individual's CWB [9]. In his 2001 study, Fox said that negative emotions and malicious interpersonal behavior, vandalism, and attacks all have an impact. And studies have shown that individuals with higher negative emotions are more sensitive to stress events. This is because they have a negative attitude towards things. When faced with stressful events, individuals with high negative emotions are more likely to attribute stress as obstructive, leading to anti-production behavior [10].

In addition, according to the affective events theory [11], it is believed that the characteristics of the working environment will cause events of different nature (positive or negative events), and the experience and cognitive evaluation of these events will cause the individual's emotional response, and ultimately the individual's behavioral responses [12]. For example, in the workplace, if the boss often publicly criticizes the members of the organization, the members will experience the negative emotions of anger and dissatisfaction, thus taking the work of absenteeism or deliberately delaying the time to retaliate against the boss's criticism. It can be seen that the negative emotion is the relationship between work stress and anti-production behavior. So the following hypotheses are proposed:

Hypothesis 1: Work stress is positively related with the counterproductive behaviors.

\subsection{The Moderate Role of Attachment Orientation}

In the 1970s, the famous psychologist Bowlby proposed attachment theory. Bowlby believed that human beings were born with the need to seek and maintain close relationships with others. They defined attachment as a tendency to seek strong emotional bond between an individual and another person of special significance [13]. The internalization relationship of this attachment style will manifest itself in different internal working modes when individuals interact with others after adulthood [14]. This internal working mode leads to different activation strategies of the attachment system, which unconsciously affects the individual's basic attitude towards the outside world, including the individual's basic sense of security, the expectation of social support in a stressful situation, the effort to seek support, and the corresponding. The situational factors have a very important impact on the individual's stress response and mental health [15].

Two parts of the internal working model are the self-model and the other-model. The self-model refers to the individual's cognition of whether he or she is worthy of being loved [16], describing whether "individual can attract objects to respond effectively"; the model of others refers to the individual's perception of whether the attachment is available and reactive. Describes whether 
"attachment objects will respond when they need support and protection" [17]. Bartholomew distinguishes four different types of attachment styles based on the internal working model of attachment: secure (positive self-model and positive other-model), avoidance (positive self-model and negative other-model), fearful (negative self-model and negative other-model), preoccupied (negative self-model and positive other-model) [18]. And the relationship questionnaire with two dimensions of anxiety and avoidance was designed. This classification is a widely accepted method of current research.

Attachment-anxious individual has a positive attitude towards the relationship of others and actively seeks help from others in the face of stressful events. Through their past attachment experience, anxious individuals have a negative belief in themselves and low self-efficacy, so they will actively seek help from others. For attachment avoiding individuals will escape the pressure and deliberately ignore the pressure for the sake of the negative model of others which believes that others do not provide timely help when they need help and support. The result will lead to their inability to effectively solve the pressure, thereby further increasing the pressure experienced by individuals, increasing the possibility of individuals implementing anti-production behavior. Based on the above, this paper proposes the hypothesis:

Hypothesis 2: Attachment anxiety can moderate the relationship between stress and CWB. Specifically, individuals with high attachment anxiety will reduce the positive relationship between work stress and anti-production behavior.

Hypothesis 3: Attachment avoidance can moderate the relationship between stress and CWB. Specifically, individuals who are attached to avoiding high individuals will increase the positive relationship between work stress and anti-production behavior.

Combining the hypothesis, the research model is shown as Figure 1.

\section{Materials and Methods}

\subsection{Participants}

A total number of 400 questionnaires were distributed, and 307 questionnaires were returned. The questionnaire recovery rate was $76.8 \%$. The gender composition of the participants was $29 \%$ for men and $71 \%$ for women; $41.4 \%$ for ages under 25 years, $50 \%$ for ages 26 to $45,8.6 \%$ for people over 45 years old, and $52.9 \%$ for private sector participants. The number of participants in institutions and state administrative agencies is $19 \%$.

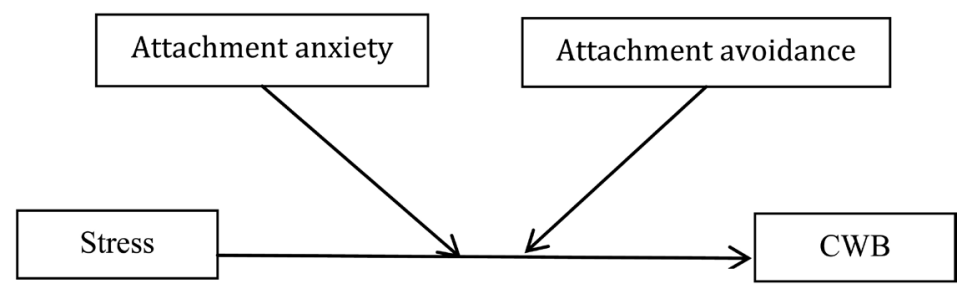

Figure 1. The research model. 


\subsection{Measures}

- Work Stress: Scale In this study, Ma Jianhong revised the Work Stress Awareness Scale in line with the Chinese situation on the basis of the Rizzo's original scale in 1997. The scale includes psychological experience, physiological response and emotional response to work stress, totaling 11 questions. The coefficient of internal consistency (Cronbach's alpha) of the scale was $\alpha=0.906$, and the validity of the scale(KMO) was 0.915 .

- CWB Scale: The CWB Scale uses a two-dimensional scale designed by Bennett \& Robinson for a total of 19 items, including anti-production behaviors of organizational pointing (12) and interpersonal pointing (7). Taking into account the reality of the Chinese situation, and drawing on the revision of the scale by domestic scholars, this paper removes the "drug abuse" pointed by the organization and the interpersonal orientation of "reviewing ethnicity, religion and ethnicity at work" when applying the items. On the other hand, the data related to CWB is self-reporting, and the respondents may be sensitive to such negative behaviors due to social claims, and may be concealed when selecting items, to a certain extent. Affect the reliability of data, so this article is filled in anonymously, which can reduce the impact of social appeal to a certain extent. The coefficient of internal consistency (Cronbach's alpha) of the scale was $\alpha=0.866$, and the validity of the scale (KMO) was 0.872 .

- Attachment Orientation Scale: The attachment type is measured by Bernnan's intimate relationship experience questionnaire, and then revised by the Chinese scholar Li Tonggui. This questionnaire has a total of 36 items, which are divided into two dimensions: attachment avoidance and attachment anxiety. The 7-point scoring method is adopted, and the respondents are asked to make choices for each item according to their feelings in the intimate relationship of close friends. Some of these topics are scored in reverse. The coefficient of internal consistency (Cronbach's alpha) of the scale was $\alpha=0.838$, and the validity of the scale (KMO) was 0.867 .

\subsection{Procedure}

The questionnaire was distributed online. The respondents finished this questionnaire following the instruction. Of the 400 questionnaires distributed, 307 were returned giving a return rate of $76.8 \%$. However, only $278(90.6 \%)$ were properly filled and used for data analysis while 29 were incompletely filled and were discarded. The confidentiality of the information obtained from the respondent was guaranteed.

\subsection{Results}

The data obtained were analyzed using hierarchical multiple regression analysis in order to establish the relationship of job stress (independent variable), attachment orientation (moderate variable) and counterproductive work behavior (dependent variable). In step 1, I entered the four control variables. In step 2 and 
3 , I entered the main effects and in step 4, I entered the interaction terms as discussed in this study.

Results in Table 1 shows that of the control variables, no control variables were significantly correlated with CWB. Job stress $(r=0.586, p<0.01)$, attachment avoidance $(\mathrm{r}=0.334, \mathrm{p}<0.01)$, attachment anxiety $(\mathrm{r}=0.192, \mathrm{p}<0.05)$ were significantly correlated with CWB.

Table 2 shows the results from the regression analysis between job stress and CWB. After controlling for gender, age, enterprise nature in step 1, job stress ( $\beta$ $=0.0 .408, \mathrm{p}<0.01)$ in step 2 , independently explained $17 \%$ of the variance in CWB, supporting hypothesis 1 .

Table 3 shows the hierarchical regression results between attachment anxiety and CWB. Frist, controlling for gender, age, enterprise nature in step 1, job stress $(\beta=0.0 .408, \mathrm{p}<0.01)$ in step 2 , independently explained $17 \%$ of the variance in $\mathrm{CWB}$. In the third step, the attachment anxiety was significantly related to CWB $(\beta=0.270, \mathrm{p}<0.01)$. In the final step of the regression analysis, the interaction

Table 1. Means, standard deviations and intercorrelation matrix of the demographic, predictor variable and CWB.

\begin{tabular}{|c|c|c|c|c|c|c|c|c|c|c|}
\hline Variables & M & SD & 1 & 2 & 3 & 4 & 5 & 6 & 7 & 8 \\
\hline Gender & - & - & - & & & & & & & \\
\hline Age & 1.88 & 0.94 & - & - & & & & & & \\
\hline Education & 2.58 & 1 & - & - & - & & & & & \\
\hline Enterprise Nature & 3.66 & 1.28 & - & - & - & - & & & & \\
\hline Job stress & 31.11 & 7.39 & $0.183^{\star *}$ & -0.058 & -0.031 & 0.055 & - & & & \\
\hline CWB & 23.09 & 6.15 & -0.066 & -0.05 & -0.091 & -0.086 & $0.586^{\star *}$ & - & & \\
\hline attachment avoidance & 66.91 & 11.31 & $0.170^{*}$ & $-0.144^{*}$ & -0.022 & -0.019 & $0.392^{* *}$ & $0.334^{* *}$ & - & \\
\hline attachment anxiety & 60.73 & 14.5 & $0.217^{\star *}$ & $-0.171^{\star}$ & -0.063 & 0.004 & $0.409^{* *}$ & $0.326^{* *}$ & $0.192^{\star}$ & - \\
\hline
\end{tabular}

$\mathrm{N}=278, \mathrm{AV}=$ Attachment $\mathrm{CWB}=$ Counterproductive work behavior, ${ }^{\star} \mathrm{p}<0.05,{ }^{* *} \mathrm{p}<0.01$

Table 2. Regression analyses predicting CWB from job stress.

\begin{tabular}{cccc}
\hline \multirow{2}{*}{ Model } & \multicolumn{2}{c}{ Unstandardized Coefficients } & Standardized Coefficients \\
\cline { 2 - 4 } (Constant) & 27.34 & Std. Error & Beta \\
Gender & -2.687 & 3.242 & -0.179 \\
Age & -0.438 & 0.985 & -0.06 \\
Education & -0.839 & 0.47 & -0.121 \\
Enterprise Nature & -0.636 & 0.444 & -0.118 \\
Job stress & 0.383 & 0.339 & $0.408^{* *}$ \\
$R^{2}$ & & 0.06 & \\
$\Delta R^{2}$ & & 0.19 & \\
F & & 9.788 & \\
\hline
\end{tabular}

$\mathrm{CWB}=$ Counterproductive work behavior, ${ }^{* *} \mathrm{p}<0.01$. 
term of job stress $\times$ attachment anxiety affectivity was significantly related to CWB $(\beta=0.190, \mathrm{p}<0.05)$ in a positive way which is contrary to hypothesis 2 . Thus, hypothesis 2 was not supported.

Table 4 shows the hierarchical regression results between attachment avoidance and CWB. In the final step of the regression analysis, the interaction term of job stress $\times$ attachment anxiety affectivity was significantly related to $\mathrm{CWB}$ ( $\beta$ $=0.144, \mathrm{p}<0.05)$ supporting hypothesis 3 .

\section{Conclusions}

The research object of this study is the individual in the enterprise. The raw data

Table 3. The hierarchical regression results between attachment anxiety and CWB.

\begin{tabular}{ccccc}
\hline Variables & Model 1 & Model 2 & Model 3 & Model 4 \\
\hline (Constant) & & & & \\
Gender & -0.105 & -0.179 & -0.214 & -0.198 \\
Age & -0.074 & -0.06 & -0.022 & -0.016 \\
Education & -0.122 & -0.121 & -0.108 & -0.114 \\
Enterprise Nature & -0.09 & -0.118 & -0.119 & -0.115 \\
Job stress & & $0.408^{* *}$ & $0.326^{* *}$ & $0.337^{* *}$ \\
attachment anxiety & & & $0.270^{* *}$ & $0.244^{* *}$ \\
Job stress ${ }^{*}$ attachment anxiety & & & & $0.190^{*}$ \\
$R^{2}$ & 0.029 & 0.19 & 0.251 & 0.286 \\
$\Delta R^{2}$ & 0.011 & 0.17 & 0.229 & 0.262 \\
$\mathrm{~F}$ & 1.591 & 9.788 & 11.609 & 11.858 \\
\hline
\end{tabular}

$\mathrm{CWB}=$ Counterproductive work behavior, ${ }^{*} \mathrm{p}<0.05,{ }^{* *} \mathrm{p}<0.01$.

Table 4. The hierarchical regression results between attachment avoidance and CWB.

\begin{tabular}{ccccc}
\hline Variables & Model 1 & Model 2 & Model 3 & Model 4 \\
\hline Constant) & & & & \\
Gender & -0.105 & -0.179 & -0.214 & -0.191 \\
Age & -0.074 & -0.06 & -0.022 & -0.02 \\
Education & -0.122 & -0.121 & -0.108 & -0.119 \\
Enterprise Nature & -0.09 & -0.118 & -0.119 & -0.111 \\
Job stress & & $0.408^{* *}$ & $0.326^{* *}$ & $0.341^{* *}$ \\
attachment avoidance & & & $0.260^{* *}$ & $0.232^{* *}$ \\
Job stress ${ }^{*}$ attachment avoidance & & & & $0.144^{*}$ \\
$R^{2}$ & 0.029 & 0.19 & 0.245 & 0.265 \\
$\Delta R^{2}$ & 0.011 & 0.17 & 0.223 & 0.24 \\
F & 1.591 & 9.788 & 11.232 & 10.651 \\
\hline
\end{tabular}

$\mathrm{CWB}=$ Counterproductive work behavior, ${ }^{\star} \mathrm{p}<0.05,{ }^{* *} \mathrm{p}<0.01$. 
are obtained mainly through questionnaires. The SPSS22.0 software is used to operate and analyze the sample data, and to the relationship between work stress and production behavior and its effect. The mechanism was further explored and analyzed. At the same time, it proves the mediating role of negative emotions in the relationship between the two, and the adjustment effect of attachment orientation between work stress and anti-production behavior. The study has obtained the following conclusions:

First, the relationship between work stress and anti-production behavior is supported. From the empirical analysis results, work stress can positively predict counterproductive work behaviors. This shows that the work pressure faced by individuals in the workplace, such as workload, interpersonal stress, can lead to changes in individual emotions and behaviors. When faced with stress, individuals are prone to negative emotions such as anxiety, impatience and tension. Changes can cause individuals to make certain inappropriate behaviors. The results are in full compliance with the stress-emotional model.

Second, by using hierarchical regression analysis, the attachment orientation has a significant moderate effect on the relationship between work stress and CWB. The results show that the personality trait of attachment orientation affects the individual's response to stress events in the workplace. On the one hand, from the empirical results, attachment avoidance can effectively regulate the relationship between work stress and counterproductive work behavior. The individuals with a high degree of attachment avoidance will suppress their attachment needs in the face of stress, due to the rejection and indifference of the object of attachment in past interactions. They try to be self-reliant and independent by staying away from others. Avoidant individuals often suppress or ignore related threats to prevent activation of the attachment system. Therefore, when faced with stress events in the workplace, the avoidant individuals will deliberately ignore the pressure based on past experience, so that the pressure will not be resolved in time, thereby increasing the possibility of individuals implementing CWB. On the other hand, through the above empirical analysis, attachment anxiety has a positive adjustment effect on the relationship between work stress and counterproductive work behavior, which is contrary to the research hypothesis of this paper. This shows that for attachment anxiety individuals, in the face of stressful events, although they actively seek help from others, the stress events have not been alleviated, thus increasing the possibility of implementing counterproductive work behavior. For this result, this paper combines the existing literature analysis and believes that the possible reason is that for attachment anxiety individuals, although they actively seek help from others, they tend to adopt the "over-activation strategy" because of past attachment experience, which means individual may get support from others through excessive entanglement. Such behavior will lead to resentment of seeking objects and will not get the help the individual wants. Therefore, even if the individual actively seeks the support of others, such behavior is often ineffective [19], but it will increase the possibility of individuals implementing anti-production behavior. 


\section{Recommendation}

This paper verifies the impact of work stress on individual counterproductive work behavior through empirical methods and also introduces attachment orientation innovatively to explore attachment anxiety and attachment avoidance regulates the relationship between work stress and anti-production behavior, which proves that attachment avoidance can significantly increase the impact of work stress on anti-production behavior, and attachment anxiety also increases the impact between work stress and anti-production behavior. This is contrary to the research hypothesis of this paper. The essence of theoretical research lies in the service of practical work. The research and research in this paper have explored useful inspiration for enterprise management. details as follows:

First, conduct a comprehensive diagnosis of the organization's work. This helps the organization to clarify the specific responsibilities of each position and alleviate the problem of excessive workload and working hours of existing employees. Establish a career development consulting room. When employees encounter bottlenecks in their career development, they can seek help from the Career Development Counseling Office. The consultants provide reasonable career advice to employees based on their past work experience and future goals. The pressure generated by development.

Second, the attachment orientation should be introduced into the employee selection process. The individual attachment type is used as a personality trait evaluation standard to select suitable personnel for the enterprise. From the analysis of this paper, early attachment plays an important role in the development of a person's life. Different attachments will have different degrees of adaptation to different positions. Therefore, the type of attachment of the individual in the examination of the person and the post is conducive to the realization of the diversification of human resources employment within the organization.

\section{Future Research}

This research system investigates and studies the influence mechanism between work pressure and individual anti-production behavior, and verifies the relevant theoretical hypotheses, and discusses and analyzes the research conclusions. In addition, an empirical analysis of the mediating role of negative emotions and the regulation of attachment orientation was conducted. However, as far as this study is concerned, there are still many deficiencies and areas to be improved.

First, study the limitations of the sample. Due to the limitation of time, manpower, material resources and financial resources, this study mainly distributes questionnaires through the network, and the sample number is relatively small. At the same time, due to the large regional differences of enterprises in different regions, the characteristics of the differences in the enterprise. There is no good regional distinction. Therefore, comparative research on different enterprises in different regions can, to a certain extent, explain the relationship between employee work pressure and anti-production behavior in China's enterprise man- 
agement. In the follow-up study, continue to expand the scope of the sample and study, using longitudinal research and case analysis methods to collect more data to explore the research variables involved in the study and the relationship between them, and explore other intermediate variables at work. The intermediary between stress and anti-production behavior.

Finally, each of the study variables in the sample survey of this study used subjective evaluation measures. Although most similar studies used similar methods for sample surveys, this method could not overcome the shortcomings caused by subjective scoring. In the actual investigation, due to the individual's perceptual preference and the different working situations, the selection result of the questionnaire may have a large deviation from the actual situation. This possibility will inevitably have a certain impact on the reliability of the conclusion of this study. At the same time, this study only uses SPSS statistical analysis software for empirical research, the research level is still relatively low, and the mechanism of influence between variables cannot be further explained.

\section{Acknowledgements}

The author is grateful to Associate Professor Wenli li who consistently providing helpful comments on the survey development of this study.

\section{Conflicts of Interest}

The authors declare no conflicts of interest regarding the publication of this paper.

\section{References}

[1] Wei, F., Li, W., Lu, C., et al. (2015) Research on the Relationship between Psychological Contract Breakdown, Management Bullying and Anti-Production Behavior. Journal of Management Sciences, No. 3, 52-63.

[2] Li, L., Miao, M., Hu, M., et al. (2011) Analysis of Typical Shutdown Events in China from 2004 to 2010. China Human Resources Development, No. 3, 80-83.

[3] Geddes, D. and Baron, R.A. (1997) Workplace Aggression as a Consequence of Negative Performance Feedback. Management Communication Quarterly, 10, 433-454. https://doi.org/10.1177/0893318997104002

[4] Hamilton, V.L. (1980) Intuitive Psychologist or Intuitive Lawyer? Alternative Models of the Attribution Process. Journal of Personality and Social Psychology, 39, 767-772. https://doi.org/10.1037/0022-3514.39.5.767

[5] Zhang, L., Huang, Q., Jiang, Y, et al. (2018) Anti-Production Work Behavior: Research Perspective, Content and Design. Psychological Science Progress, 26, 306-318. https://doi.org/10.3724/SP.J.1042.2018.00306

[6] Schusterschitz, C., Danay, E. and Geser, W. (2018) Emotional Reactions to Daily Workload: The Moderating Role of Attachment Orientations. Work \& Stress, 32, 262-280. https://doi.org/10.1080/02678373.2018.1437094

[7] Xu, C. (1999) Work Stress System: Mechanism, Coping and Management. Journal of Zhejiang Normal University, No. 5, 69-73.

[8] Spector, P.E. and Fox, S. (2005) Counterproductive Work Behavior: Investigations 
of Actors and Targets. American Psychological Association, Washington DC, 151-174.

[9] Chen, P.Y. and Spector, P.E. (1992) Relationships of Work Stressors with Aggression, Withdrawal, Theft and Substance Use: An Exploratory Study. Journal of Occupational and Organizational Psychology, 65, 177-184. https://doi.org/10.1111/j.2044-8325.1992.tb00495.x

[10] Penney, L.M. and Spector, P.E. (2005) Job Stress, Incivility, and Counterproductive Work Behavior (CWB), the Moderating Role of Negative Affectivity. Journal of Organizational Behavior, 26, 777-796. https://doi.org/10.1002/job.336

[11] Weiss, H.M. and Cropanzano, R. (1996) Affective Events Theory: A Theoretical Discussion of the Structure, Sauses and Sonsequences of Affective of Experiences at Work. Research in Organizational Behavior, 18, 1.

[12] Duan, J., Fu, Q., Tian, X., et al. (2011) The Content, Application and Research Prospects of Emotional Event Theory. Advances in Psychological Science, No. 4, 599-607.

[13] Bowlby, J. (1983) Attachment: Second Edition. Attachment and Loss Series Vol. 1, Basic Books, New York.

[14] Hazan, C. and Shaver, P.R. (1990) Love and Work: An Attachment-Theoretical Perspective. Journal of Personality and Social Psychology, 59, 270-280. https://doi.org/10.1037//0022-3514.59.2.270

[15] Zhang, H. (2011) Research on the Relationship between College Students' Stress Coping Style and Their Attachment Internal Working Mode.

[16] Wang, F., Miao, D. and Xu, Y. (2016) Questionnaire and Validity of Questionnaires for Adult Attachment Internal Working Model. Chinese Journal of Clinical Psychology, No. 2, 229-234.

[17] Wen, Y. (2013) The Influence of Attachment Internal Working Model on Psychological Behavior. Journal of Shanxi University of Finance and Economics, No. S1, 56-57.

[18] Bartholomew, K. and Horowitz, L.M. (1991) Attachment Styles among Young Adults: A Test of a Four-Category Model. Journal of Personality and Social Psychology, 61, 226-244. https://doi.org/10.1037//0022-3514.61.2.226

[19] Mikulincer, M. and Shaver, P.R. (2005) Attachment Theory and Emotions in Close Relationships: Exploring the Attachment-Related Dynamics of Emotional Reactions to Relational Events. Personal Relationships, 12, 149-168. https://doi.org/10.1111/j.1350-4126.2005.00108.x 